\title{
Study of the Duration of Treatment in Drug Prescriptions Received in Pharmacies in Dakar
}

\author{
Mbathio Diop1, Serigne Dame Dieng1, Aida Kanouté1, Bineta Faye1, \\ Mansoum Ndiaye ${ }^{2}$, Cheikh Mouhamadou Mbacké Lố ${ }^{1}$, Daouda Faye ${ }^{1}$ \\ ${ }^{1}$ Department of Odontology, Faculty of Medicine, Pharmacy and Odontostomatology, Cheikh Anta Diop University, \\ Dakar, Senegal \\ ${ }^{2}$ Health Department of the African Center for Advanced Studies in Management, Dakar, Senegal \\ Email: diopmbathiosn@gmail.com
}

How to cite this paper: Diop, M., Dieng, S.D., Kanouté, A., Faye, B., Ndiaye, M., Lô, C.M.M. and Faye, D. (2021) Study of the Duration of Treatment in Drug Prescriptions Received in Pharmacies in Dakar. Open Journal of Preventive Medicine, 11, 80-89.

https://doi.org/10.4236/ojpm.2021.113008

Received: November 6, 2020

Accepted: March 21, 2021

Published: March 24, 2021

Copyright $\odot 2021$ by author(s) and Scientific Research Publishing Inc. This work is licensed under the Creative Commons Attribution International License (CC BY 4.0).

http://creativecommons.org/licenses/by/4.0/ (c) (i) Open Access

\begin{abstract}
The prescription must include the name of the drugs or products prescribed, dosage form, dosage, directions for use and duration of treatment. However, sometimes errors can occur that can have consequences for the health of patients. Our study concerns the use of medical prescriptions received in pharmacies in the Dakar department. The survey was conducted in 90 pharmacies in these communes, which represent one third of the 270 pharmacies in the department of Dakar. This allowed us to study 2700 prescriptions. The study took place from 1 December 2016 to 30 June 2017, i.e. over a period of 7 months. Our results show that neurologists and urologists have a longer average treatment time than other specialists, with an average of 120 days and 90 days of treatment respectively. Then, the specialists who take a long time the drug represent more than $27 \%$, and require renewal of the drug. In $63.90 \%$ of the cases, no notification on the duration of treatment was given by the prescriber. Only 5.39\% were only given the mention "to be renewed". At the end of our analysis, we can say that the prescription must be perfectly legible to avoid confusion by the patient or the pharmacist. The pharmacist then participates in the therapeutic education of the patient and thus helps him/her to live better with his/her disease. Therefore, socio-professional health associations and organisations must provide more continuous training on prescribing to ensure good compliance and above all avoid people buying medicines in the parallel circuit in order to better control health expenditure.
\end{abstract}

\section{Keywords}

Duration of Treatment, Prescription, Drugs 


\section{Introduction}

Medical prescription is the act of prescribing treatment on a prescription, after making a diagnosis. The prescription must mention the name of the drugs or products prescribed, the galenic form, the posology, the instructions for use and the duration of treatment [1]. Its use and distribution must be strictly controlled. Consequently, the medical prescription is the responsibility of a limited circle of health professionals; it must be easy to use by the pharmacist, the nurse and the patient or his/her family [2]. Good organization is necessary between the prescribing and delivery of medicines. By prescribing medicines and supplying them in a pharmacy, the relationship between prescriber and pharmacist should be better established. The improvement of our health care system depends on this relationship or collaboration. The medical prescription becomes the link between the prescriber and the pharmacist, who are both committed to the proper management of the patient's health problems. However, according to the WHO, $50 \%$ of medicines are not prescribed rationally, 50\% of medicines that are appropriately prescribed are not taken correctly and only less than $20 \%$ of medicines sold are used according to scientific criteria [3]. The aim of this study is to contribute to the improvement of drug prescribing and use. The objective of this work is to study the duration of treatment in the medical prescription received in pharmacies in the department of Dakar.

\section{Methodology}

\subsection{Type of Study}

This is a descriptive and transversal study. It relates the use of medical prescriptions received in pharmacies in the department of Dakar.

\subsection{Population of the Study}

The study population is the drugstores located in the department of Dakar.

\subsection{Criteria for Selection}

- Inclusion Criteria

Are selected all the prescriptions in the right form, i.e. the prescriptions where the date, the name of the patient, his weight if it is a child, the stamp and signature of the doctor and the products which must be delivered to the patient are present.

- Criteria for non-inclusion

Any non-conforming prescription, i.e. without any possibility of identifying the prescriber, the patient or both.

\subsection{Study Period and Duration}

The study took place from December 1, 2016 to June 30, 2017, i.e. a duration of 7 months. 


\subsection{Sampling}

Dakar department is divided into 19 municipalities of districts to which a number has been assigned. A drawing of lots was carried out to determine the 7 communes, i.e. one third, which will be visited. The survey was conducted in 90 pharmacies in these municipalities, which represent one third of the 270 pharmacies in the department of Dakar.

\subsection{Data Collection Procedure}

- Contact with pharmacy managers

A letter was sent to all the drugstore managers who were targeted for our survey. Dates and times for the survey were agreed upon with the managers of targeted drugstores.

- Composition of the survey team, calibration and pre-investigation

Five pharmacy thesis year students from different pharmacies were part of the investigation team. Training sessions were organized to ensure that all the investigators were calibrated in order to standardize the data collection. A pre-investigation of two pharmacies was carried out in order to identify difficulties or misunderstandings and to correct them before the final survey.

\subsection{Description of Survey Variables}

- Prescribers: Specialists who prescribe drugs

- Dosage: Report the dosage of each product if determined;

- Duration of treatment: Report the duration of each treatment if indicated;

- Patient's age, weight and gender.

\subsection{Data Collection}

Survey teams spent a week in each targeted drugstore for 3 half-days.

\subsection{Data Analysis Plan}

Results have been analyzed with epi info version 6.04 and Excel.

\section{Results}

At the end of our survey, an average of 10 prescriptions was collected per day in each of the 90 pharmacies where the survey was conducted. This allowed us to study 2700 prescriptions.

1) Distribution of types of specialists (Figure 1)

2) Duration of Treatment

- Notification to the patient of the duration of treatment by the doctor

In $63.90 \%$ of the cases, no notification on the duration of the medication was given by the prescriber as shown in Table 1:

- Average treatment time by specialty

Neurologists and urologists prescribed treatments that lasted longer on average than those of other specialists, with an average of 120 days and 90 days of 


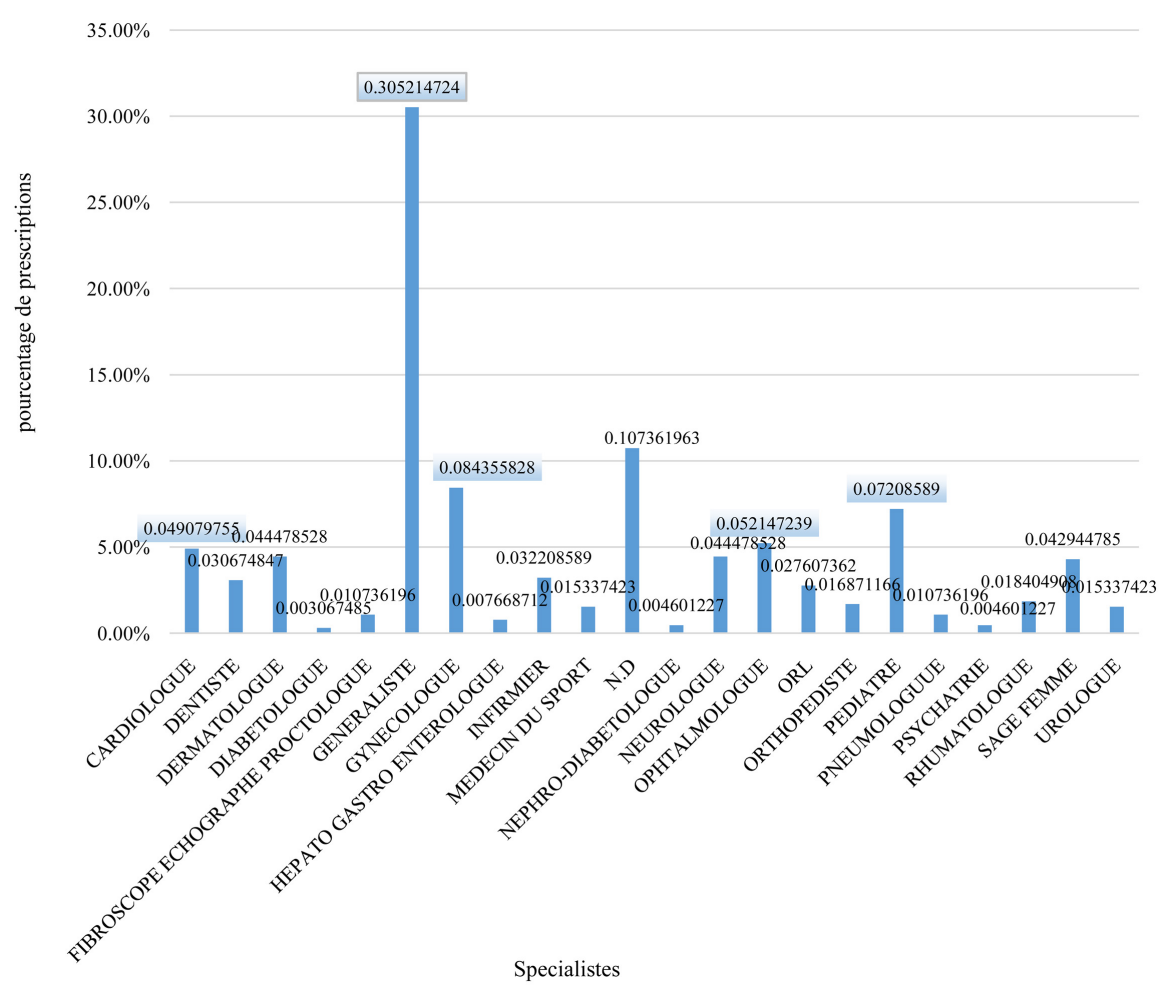

Figure 1. Distribution of prescribers according to prescriptions.

Table 1. Notification on the duration of treatment by the doctor according to the number of prescriptions.

\begin{tabular}{cc}
\hline Prescriptions & Percentage Prescriptions (\%) \\
\hline Number of specified treatment days & 30.71 \\
With only the words "to be renewed" & 5.39 \\
Without any notification & 63.90 \\
TOTAL & 100 \\
\hline
\end{tabular}

treatment respectively. In addition, the duration of treatment for oral conditions ranges from 3 to 6 days. See Figure 2 .

Neurologist, urologist, diabetic gynecologist, rheumatologist, cardiologist, gastroenterologist, dermatologist, and psychiatrist, who represent more than $27 \%$, require renewal of the drug.

\section{Discussion}

\subsection{Duration of Treatment}

- Notification on duration of treatment

More than half of prescribers (63.90\%) did not give any written information to patients regarding the duration of treatment. This could create a problem especially since often in our African context illiterate patient could afford to renew the treatment or even stop it before the end of the medication or as soon as the symptoms disappear. Doctors must specify if the drug is to be renewed and how 


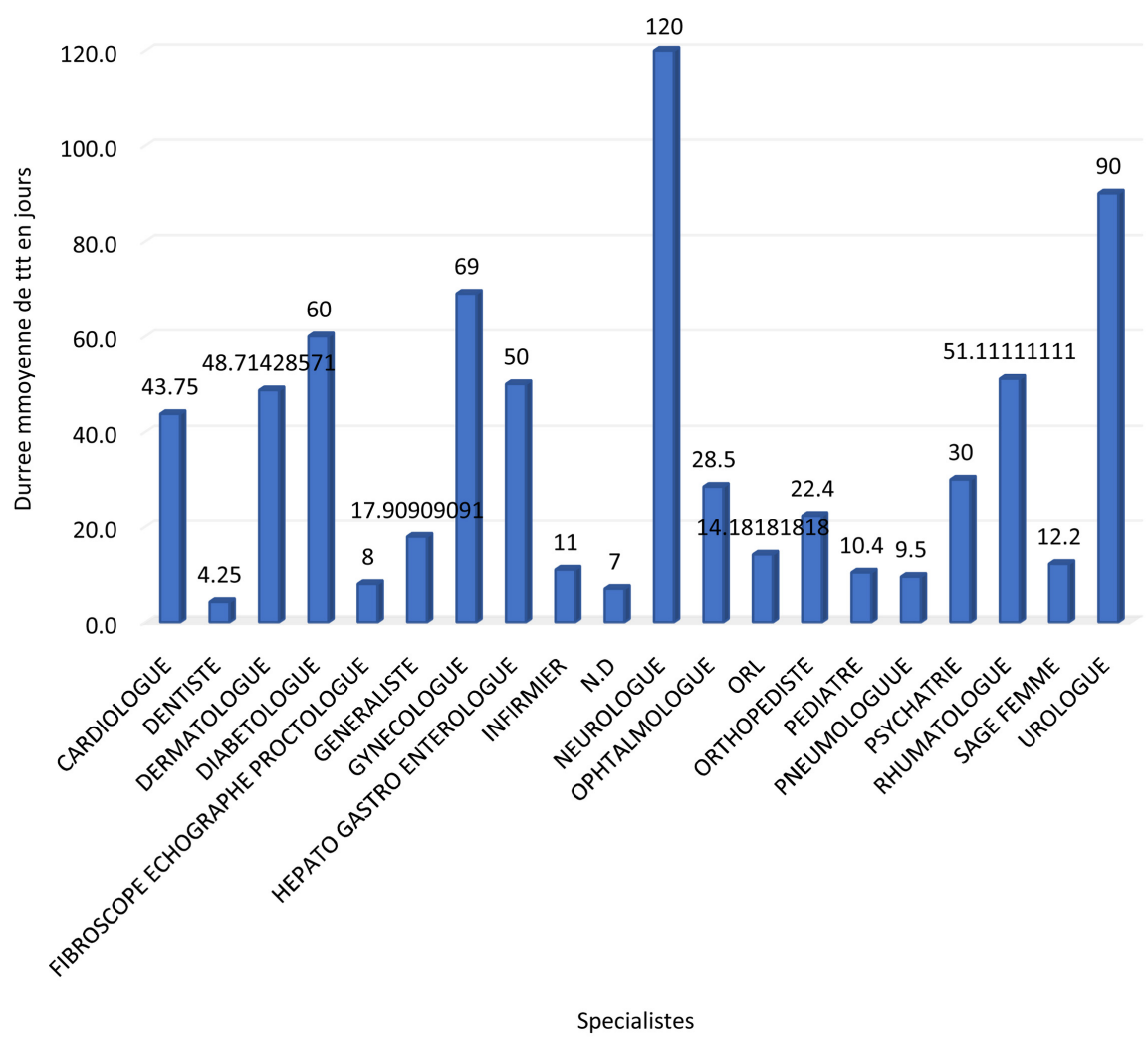

Figure 2. Average of treatment duration by specialist.

many times, specifying the exact duration of the drug's use. It would also be important for the doctor to inform the patient that the drug prescription given to him or her cannot be applied to another person. Indeed, in our African context, the patient often advises his or her relatives to take the same drugs if he or she seems to be developing the same symptoms. Diop et al's study reveals that $37 \%$ of households use traditional medicines and $32 \%$ self-medicate for dental pain [4]. In addition, the pathology treated, patient's condition and disease history are the main factors on which the doctor will base his prescriptions. In all cases, it should be specified, as the absence of an indication of the duration of the treatment most often leads to non-compliance with the treatment. According to Sondo, the main errors observed in prescribing are: failure to mention the duration of treatment, posology, galenic form, drug dosage or inadequate mention of the drugs [2]. Most prescriptions are valid for three months. Prescriptions are generally renewable for periods of up to one or three months. Contraceptives are renewable for one renewal per three-month period [1].

Drugs appear to be expensive in Senegal. The cost of the drugs is affordable, while the remaining $49.5 \%$ of the population describes them as expensive. This does not encourage patients to renew their treatment. Failure to renew treatment can lead to resistance to certain drugs and, above all, to therapeutic failure [5].

\subsection{Average Treatment Duration}

Treatment duration is higher for neurologists, urologists, gynaecologists, diabe- 
tologists and rheumatologists with 120 days, 90 days, 69 days, 60 days and 51.1 days respectively. Neurological diseases are generally long-term conditions, which makes treatment longer. The acceptance of treatment by patients was an issue raised by some participants, especially among depressed patients [6].

However, respecting the criteria of the depression practice guidelines can reduce drug costs. But $5.39 \%$ of prescriptions only carry the mention "to be renewed". We found that all diseases with an average duration of more than 30 days require the renewal of the medication. Therefore, François and Bosson link the quality of the prescription to the use of a software program for entering drug prescriptions [7] [8].

The most commonly reported problems regarding the application of e-prescriptions were found to be system-induced problems (26.5\%) and internet problems (19.9\%) [9].

The same is true for diabetes, which is a chronic disease. The duration of treatment certainly plays an important role and the management of a chronic disease is much more difficult for patients for two main reasons: tiredness and a lack of perception of the beneficial impact of treatment [10].

In gynaecology, treatments are generally not very long in case of infection. Ovules are used for an average of one week and the use of antibiotics, if necessary, can be extended to three weeks for some protocols [11]. Treatments can be much longer in the case of sterility.

In urology, female cystitis: initial cystitis and its treatment with a single dose or with fluoroquinolones (3 days) is the shortest treatment [12]. The treatment can be long as in men in case of prostatitis. The prevalence of prostatitis ranges from $5 \%-9 \%$ in the general population and it is estimated that $50 \%$ of men will develop prostatic disease at some point in their lives [13]. Cytobacteriological examination of the urines reveals urinary tract infections in $48 \%$ to $71 \%$ of cases resulting in a treatment duration of four to six weeks [14]. In case of persistent symptoms, treatment should be extended for six to 12 weeks [15].

However, it is important to improve access to antibiotics for therapeutic purposes while minimizing the overuse of antibiotics that causes problems in the resistant population [16]. Antibiotic overuse is illustrated by the study by Pouwels et al which found that of the 931,015 included consultations that resulted in an antibiotic prescription, approximately 1.3 million days exceeded the recommended guideline [17].

In rheumatology, treatment can be long as in rheumatoid arthritis. The clinical efficacy of combination therapies, even in the absence of biotherapy, begins at six months and continues at twelve, eighteen and twenty-four months [18]. The characteristics of the disease may also influence treatment compliance. It is evident that adherence to the treatment will be better if the patient can immediately verify the beneficial effects of the treatment (thanks to the pain elimination in the case of an algic pathology). In the case of dental diseases, for example, the duration of treatment varies from 3 to 6 days according to our study. the 
study was to evaluate the appropriateness of antibiotics prescriptions by Lebanese dentists to patients with endodontic abscesses and their compliance with the guidelines show that antibiotics were also prescribed unnecessarily to $17 / 42$ patients with a chronic endodontic abscess [19].

However, the duration of the treatment depends on the type of pathology. In the case of chronic diseases, the treatment can be extended, and this requires a follow-up for good compliance [20], but this long-term prescription must take into account secondary effects [21].

Diouf et al. study showed that $83.5 \%$ of dentists reported having experienced at least one case of undesirable effects during their practice. Antibiotics remain the drug class most associated with the occurrence of these undesirable effects [22].

In the end, good prescribing is important. According to the study by Krishnapillai et al., the evaluation of 9199 prescriptions from 344 physicians showed that about $37.2 \%$ (95\% CI: $34.9 \%-39.4 \%$ ) of the prescriptions were of good quality, and $48.2 \%$ (95\% CI: $42.9 \%-53.7 \%$ ) of the physicians provided quality prescriptions. Factors associated with prescription quality were knowledge of NCD guidelines, hospital quality certifications and use of patient data management software [23].

However, some limits of the study are the inclusion of drugs sold in health structures (Bamako Initiative), would have allowed us to better assess and give more reliable results regarding prescriptions in general. More so as prescription of generic drugs plays an important role in accessing health care [24].

\section{Conclusion}

Prescribers need to listen to patients. They must give them enough information about their pathology and the drugs prescribed. The prescription must be perfectly readable to avoid confusion by patient or pharmacist. Pharmacists must deliver drugs in according to the prescription. He must be able to provide advice regarding the disease and the role of the drugs. He then participates in the therapeutic education of the patient and thus helps him to better live his disease. Quality of prescription writing is crucial for a good understanding and for the different actors to speak the same language. Moreover, average treatment duration for neurologists, urologists, gynaecologists, diabetologists and rheumatologists remains high. As a result, treatment can be more expensive. Similarly, drug expenditure is an important part of the policy to control health expenditure. Therefore, associations and socio-professional organizations in the field of pharmacy (trade unions, orders, and associations) must do more training on prescription for good compliance and especially prevent people from buying drugs in the informal sector.

\section{Conflicts of Interest}

The authors declare no conflicts of interest regarding the publication of this paper. 


\section{References}

[1] Conseils nationaux des Ordre de santé de France (2012) Comment déployer la prescription électronique? Clio santé.

[2] Sondo, B., Ouédraogo, V., Ouattara, T.F., Garane, P., Savadogo, L., Kouanda, S. and Guissou, I.P. (2002) Etude de la qualité rédactionnelle des ordonnances médicales à la caisse de sécurité sociale d'Ouagadougou. S.F.S.P. Santé Publique, 1, 31-36. https://doi.org/10.3917/spub.021.0031

[3] Organisation mondiale de la santé (2002) Promouvoir l'usage rationnel des médicaments: Éléments principaux.

[4] Diop, M., Kanouté, A., Diouf, M., Ndiaye, A.D., Lo, C.M., Faye, D. and Cissé, D. (2017) Behavior of the Access to Oral Health Care in Senegal. Edorium ${ }^{m x}$ Journal of Public Health, 4, 58-68.

[5] Diop, M., Kanouté, A., Diouf, M., Ndiaye. A.D., Sougou, N.M. and Lo, C.M. (2018) Assessment of the Accessibility of Oral Health Care of Senegalese Households. International Journal of Medical and Health Research, 4, 12-17.

[6] Poucher, M., Cherrier, C., Poucher, A.C. and Patrizio, P.D. (2016) Evolution des pratiques en médecine générale dans la prise en charge des douleurs neuropathiques S.F.S.P. Santé Publique, 4, 505-516. https://doi.org/10.3917/spub.164.0505

[7] Bosson, J.L., Sang, B., Vermeulen, E., et al. (1996) Informatisation de la prescription dans l'unité de soins, méthodologie d'implantation et évaluation comparative de trois logiciels. Journal of Medical Economics, 14, 273-278.

[8] François, P., Bontemps, H., Bertrand, D., Bosson, J.L. and Calop, J. (1997) Etude de la qualité de la formulation des prescriptions médicamenteuses à l'hôpital. Thérapie, 52, 569-571.

[9] Bulut, S., Yıldız, A. and Kaya, S. (2019) Evaluation of Transition to Electronic Prescriptions in Turkey: Perspective of Family Physicians. International Journal of Health Policy and Management, 8, 40-48. https://doi.org/10.15171/ijhpm.2018.89

[10] Scheen, A.J. and Giet, D. (2010) Non Compliance to Medical Therapy: Causes, Consequences, Solutions. Revue Medicale de Liege, 65, 239-245.

[11] Bourret, A. and Fauconnier, A. (1993) Management of Uncomplicated Pelvic Inflammatory Disease. Infectious Diseases in Obstetrics and Gynecology, 1, 123-129.

[12] Jones, R.N., Beach, M.L. and Pfaller, M.A. (2001) Spectrum and Activity of Three Contemporary Fluoroquinolones Tested against Pseudomonas aeruginosa Isolates from Urinary Tract Infections in the Sentry Antimicrobial Surveillance Program. Europe and the Americas, 2000: More Alike than Different. Diagnostic Microbiology and Infectious Disease, 41, 161-163. https://doi.org/10.1016/S0732-8893(01)00287-5

[13] Adehossi, E., Ranque, S. and Brouqui, P. (2002) Le traitement des prostatites. La Revue de Médecine Interne, 23, 999-1005. https://doi.org/10.1016/S0248-8663(02)00726-9

[14] Dahami, Z., Sarf, I., Dakir, M., et al. (2003) Prostatite granulomateuse (à propos de 6 cas). Annales d Urologie, 37, 299-301. https://doi.org/10.1016/S0003-4401(03)00071-8

[15] Delavierre, D., Rigaud, J., Sibert, L., et al. (2010) Traitements spécifiques de la prostatite chronique bactérienne et du syndrome douloureux pelvien chronique. Progrès en Urologie, 20, 1066-1071. https://doi.org/10.1016/j.purol.2010.09.017

[16] Mendelson, M., Røttingen, J.A., Gopinathan, U., et al. (2016) Maximising Access to Achieve Appropriate Human Antimicrobial Use in Low-Income and Middle-Income 
Countries. The Lancet, 387, 188-198.

https://doi.org/10.1016/S0140-6736(15)00547-4

[17] Pouwels, K.B., Hopkins, S., Llewelyn, M.J., Walker, A.S., McNulty, C.A.M. and Robotham, J.V. (2019) Duration of Antibiotic Treatment for Common Infections in English Primary Care: Cross Sectional Analysis and Comparison with Guidelines. BMJ, 364, 1440. https://doi.org/10.1136/bmj.1440

[18] Ndongo, S., Pouye, A., Lekpa, F.A., et al. (2012) Problématique du traitement de fond des rhumatismes inflammatoires en Afrique subsaharienne: Évolution à six mois de 205 patients sénégalais atteints de polyarthrite rhumatoïde. Journal of Medicine and Tropical Health, 22, 385-389.

[19] Ramli, G.A.A., Mokhbat, J., Cochelard, D., Lemdani, M., Haddadi, A. and Ayoub, F. (2020) Appropriateness of Therapeutic Antibiotic Prescriptions by Lebanese Dentists in the Management of Acute Endodontic Abscesses. Cureus, 12, e7327.

[20] Redelico, T.J., Walton, S.M., LaFollette, J., Adams, C.M. and Bernal, M.L. (2018) Assessment of Provider Adherence to Recommended Monitoring Parameters for Oral Anticancer Medications. Journal of Oncology Practice, 14, 446-450.

https://doi.org/10.1200/JOP.17.00018

[21] Hardy, A.C. (2019) Le bénéfice du doute? Incertitude et gestion des effets indésirables médicamenteux. Revue française des affaires sociales, 3, 35-52.

https://doi.org/10.3917/rfas.193.0035

[22] Diouf, M., Bodian, S., Lo, C.M.M., Cisse, D., Faye, D., Touré, B. and Fall, M. (2013) Pharmacovigilance chez les chirurgiens-dentistes: Enquête dans la région de Dakar, Sénégal. Santé Publique, 1, 69-76. https://doi.org/10.3917/spub.131.0069

[23] Krishnapillai, V., Nair, S., Anand, T.N., Sreelal, T.P. and Soman, B. (2020) Quality of Medical Prescriptions in Diabetes and Hypertension Management in Kerala and Its Associated Factors. BMC Public Health, 20, 193. https://doi.org/10.1186/s12889-020-8214-y

[24] Dussol, A. (2009) Le médicament générique, Collection: Que sais-je? Éditeur: Presses Universitaires de France, Paris, 128. 


\section{Appendix: Survey Form}

\begin{tabular}{|c|c|c|c|c|c|c|c|c|c|c|}
\hline $\mathrm{N}^{\bullet}$ & $\begin{array}{c}\text { Place of } \\
\text { prescription }\end{array}$ & $\begin{array}{l}\text { Prescriber } \\
\text { Specialty }\end{array}$ & $\begin{array}{l}\text { Prescribed } \\
\text { products }\end{array}$ & $\begin{array}{l}\text { Corresponding } \\
\text { molecules }\end{array}$ & $\begin{array}{c}\text { Therapeutic } \\
\text { class }\end{array}$ & Dosage & $\begin{array}{l}\text { Duration of } \\
\text { treatment }\end{array}$ & $\begin{array}{l}\text { Patient } \\
\text { age }\end{array}$ & $\begin{array}{l}\text { Patient } \\
\text { weight }\end{array}$ & $\begin{array}{l}\text { Patient } \\
\text { gender }\end{array}$ \\
\hline
\end{tabular}

